\title{
Impaired oxidative-antioxidative balance during migraine attack
}

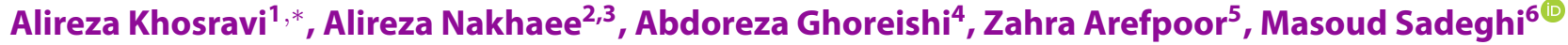

${ }^{1}$ Department of Neurology, School of Medicine, Zahedan University of Medical Sciences, Zahedan, Iran

${ }^{2}$ Department of Clinical Biochemistry, School of Medicine, Zahedan University of Medical Sciences, Zahedan, Iran

${ }^{3}$ Cellular and Molecular Research Center, Zahedan University of Medical Sciences, Zahedan, Iran

${ }^{4}$ Department of Neurology, Vali-e-Asr Hospital, School of Medicine, Zanjan University of Medical Sciences, Zanjan, Iran

${ }^{5}$ Department of Anesthesia, School of Medicine, Zahedan University of Medical Sciences, Zahedan, Iran

${ }^{6}$ Medical Biology Research Center, Kermanshah University of Medical Sciences, Kermanshah, Iran

\section{Correspondence}

Alireza Khosravi, Department of Neurology, School of Medicine, Zahedan University of Medical Sciences, Zahedan, Iran

Email: alirezakh25@gmail.com

\section{History}

- Received: Nov 04, 2018

- Accepted: Feb 06, 2019

- Published: Feb 24, 2019

DOI :

https://doi.org/10.15419/bmrat.v6i2.522

\section{Check for updates}

\section{Copyright}

( ) Biomedpress. This is an openaccess article distributed under the terms of the Creative Commons Attribution 4.0 International license.

\begin{abstract}
Background: Recent evidence has suggested that oxidative stress may play a role in the pathophysiology of migraine. In this study, we aimed to evaluate the oxidative-antioxidative status in sera of migraine patients from an Iranian population during migraine attacks. Methods: This study recruited 46 migraine patients with or without aura and 45 sex- and age-matched healthy controls. The levels of protein carbonyl (PC), malondialdehyde (MDA) and total oxidants status (TOS) were measured as the indicators of oxidative stress. The levels of total thiols (T-SH), reduced glutathione (GSH) and total antioxidant capacity (TAC) were determined as markers of antioxidant status. Oxidative stress index (OSI) was calculated by dividing TOS to TAC. Results: The serum levels of MDA $(4.10 \pm 0.70$ vs. $3.20 \pm 0.62, P=0.003)$, TOS (18.46 \pm 4.06 vs. $16.21 \pm 3.67, P=0.007)$ and OSI (1.54 \pm 0.60 vs. $1.22 \pm 0.46, P=0.006$ ) were significantly higher in migraine group compared to controls, however, no statistically significant differences of $P C$ levels were found between migraine patients and controls $(0.615 \pm 0.161$ vs. $0.517 \pm 0.126, P=0.1)$. In contrast, the levels of T-SH $(273 \pm 51.71$ vs. $310.88 \pm 53.32, P=0.001), \mathrm{GSH}(28.08 \pm 6.20 \mathrm{vs} .32 .13 \pm 5.8, \mathrm{P}=0.002)$ and TAC $(1.27 \pm 0.226$ vs. $1.41 \pm 0.26, P=0.01)$ were significantly lower in migraine patients compared to healthy controls. Conclusion: Our study showed higher levels of oxidative stress and lower levels of antioxidant status in migraine group compared to controls, which indicates the possible role of oxidative stress in triggering migraine attacks.
\end{abstract}

Key words: Migraine, Oxidative stress, Total antioxidant capacity, Total oxidants status

\section{INTRODUCTION}

Migraine is a prevalent neurological disorder characterized by severe episodic headaches with systemic or neurological symptoms ${ }^{1,2}$. There are two major types of migraines: migraines with aura and migraines without aura. Aura is experienced by about a third of migraine patients and consists of a series of transient neurological symptoms that occur in the visual system or other senses before the onset of migraine headache ${ }^{2}$. Although several genetic and environmental factors have been shown to be associated with the presence or development of migraine $^{3}$, molecular mechanisms of migraine attacks have not been clearly identified. One of the major factors lowering the threshold of the first headache symptom is the impairment of mitochondrial oxidative metabolism ${ }^{4}$. In this regard, it has been proposed that nitric oxide and oxidative stress may play a central role in migraine headache by deregulating brain blood flow ${ }^{5}$. In fact, oxidative stress originates from the imbalance between the production of reactive oxygen species (ROS) and antioxidants ${ }^{6}$. ROS are reactive oxidant molecules containing oxygen, which are formed at relatively low levels in all cells during normal metabolism and their physiological levels are necessary to maintain normal cell function ${ }^{7}$. The concentration of all oxidants in biological samples is referred to as total oxidant status (TOS) ${ }^{8}$.

The additional amounts of ROS are removed by free radical-scavenging enzymes such as superoxide dismutase, catalase, and glutathione peroxidase ${ }^{7}$. Also, there are non-enzymatic antioxidants such as ascorbic acid, vitamin E, uric acid, bilirubin, reduced glutathione (GSH), and various thiol groups on protein molecules that can act to neutralize ROS ${ }^{9}$. The reduced sulfhydryl groups of proteins and non-protein compounds are collectively known as total thiols ${ }^{10}$ and all antioxidants present in the serum are referred to as total antioxidant capacity (TAC) ${ }^{11}$. When the levels of ROS increase beyond the antioxidant capacity of the cell, a condition known as oxidative stress occurs. In such situation, free radicals may damage cellular proteins, lipids, and nucleic acids, which can potentially trigger the development of various human diseases including migraine ${ }^{12,13}$. Oxidative damage to proteins can generate protein carbonyls (PC) ${ }^{14}$ and decrease free sulfhydryl groups of proteins and other thiol-containing compounds (or total thiols). The oxidation of lipids produces malondialdehyde (MDA), which is measured as one of the indicators of oxidative stress ${ }^{15}$. In some diseases, the main patho- 
physiologic basis may come from the activation of oxidative stress and inactivation of antioxidant processes $^{16,17}$. Studies have shown that high levels of oxidative stress are associated with an increase in migraine risk. Given the fact that both genetics and environmental factors can affect migraine and oxidative stress ${ }^{18}$, this study was designed to examine the association of non-enzymatic oxidative stress markers with migraine headache in an Iranian population sample.

\section{METHODS}

\section{Patients}

This case-control study was approved by the Ethics Committee of Zahedan University of Medical Sciences and recruited 46 migraine patients with or without aura during attacks presenting at public or private clinics in Zahedan, Iran in 2014. Migraine was diagnosed based on the International Headache Society (IHS) criteria, 2nd edition ${ }^{1}$. This study excluded patients with the presence of other types of headaches, history of diabetes mellitus, tuberculosis, malaria, history of any types of malignancies, depression, underlying active systemic or inflammatory disorders, or history of using any vitamins or antioxidant supplements. Meanwhile, 45 sex- and age-matched healthy individuals without any history of migraine from medical students and university personnel were selected as the controls. An informed written consent form was sent to all participants. Following overnight fasting, blood samples were taken from cases and controls. Coagulation serum samples were obtained by centrifugation, which were then aliquoted for each test and kept at $-70{ }^{\circ} \mathrm{C}$ until analysis. Each analysis was conducted in duplicates under similar conditions on the same day.

\section{Biochemical assays}

\section{Chemical materials}

Potassium persulfate, xylenol orange, sulfuric acid, sodium chloride, hydrogen peroxide, glycerol, sulfosalicylic acid (SSA), sodium phosphate, orthophosphoric acid, ferric chloride and TBA (2-thiobarbituric acid: 4, 6- dihydroxy-2mercaptopyrimidine) were purchased from Merck. ABTS [2, 2-azinobis (3-ethylbenzothiazoline-6sulfonate)], Trolox, Ortho-dianisidine, Malondialdehyde standard (1,1,3,3-tetramethoxypropane), DTNB (5,5'-dithiobis-2-nitrobenzoic acid) and reduced glutathione (GSH) were obtained from Sigma.

\section{Total antioxidant capacity (TAC) assay}

The TAC of serum was measured based on the discoloration of 2, 2-azinobis 3-ethylbenzothiazoline6-sulfonate radical cation $\left(\mathrm{ABTS}^{*}+\right)$ by antioxidants present in the sample ${ }^{19}$. ABTS $^{*}+$ was produced by incubation of $7 \mathrm{mM}$ ABTS aqueous solution with 2.5 $\mathrm{mM}$ potassium persulfate and allowing the mixture to remain in the dark at room temperature for 12 16 hours before use. To measure sample TAC and $\mathrm{ABTS}^{*}+$, stock solution was diluted in deionized water until its absorbance at $734 \mathrm{~nm}$ reached 0.70 . One $\mathrm{mL}$ of diluted $\mathrm{ABTS}^{*}+$ was added to $10 \mu \mathrm{L}$ of serum, then the absorbance was read ten minutes after the initial mixing. The TAC was calculated using Trolox as a standard antioxidant and the result was expressed as $\mu \mathrm{M}$ Trolox.

\section{Total oxidant status (TOS) assay}

The TOS levels of the serum were determined using Erel's method that was based on the oxidation of ferrous ion-O-dianisidine complex to ferric ions by oxidants present in the sample ${ }^{20}$. The ferric ions in acidic medium formed a colored complex with xylenol orange. Briefly, a solution of $900 \mu \mathrm{L}$ of $\mathrm{H}_{2} \mathrm{SO}_{4} 25 \mathrm{mM}$ containing $150 \mu \mathrm{M}$ of xylenol orange, $140 \mathrm{mM} \mathrm{NaCl}$ and $1.35 \mathrm{M}$ glycerol was mixed with $100 \mu \mathrm{l}$ of serum or standard TOS. Then, $45 \mu \mathrm{l}$ of solution containing 5 $\mathrm{mM}$ ferrous ion and $10 \mathrm{mM} \mathrm{O}$-dianisidine in $\mathrm{H}_{2} \mathrm{SO}_{4}$ $25 \mathrm{mM}$ was added to the mixture. After 5 minutes, color intensity was measured spectrophotometrically at $560 \mathrm{~nm}$. TOS were calculated from a standard curve using hydrogen peroxide as a standard TOS and the results were expressed in $\mu \mathrm{M} \mathrm{H}_{2} \mathrm{O}_{2}$ Equivalent/L.

\section{Oxidative stress index}

Oxidative stress index (OSI) was calculated using the following equation: OSI $=\left[\mathrm{TOS}\left(\mu \mathrm{mol} \mathrm{H}_{2} \mathrm{O}_{2}\right.\right.$ Equivalent/L)/TAC ( $\mu$ mol Torolox Equivalent/L)] x 100.

\section{Total thiol assay}

The levels of total thiols were measured spectrophotometrically according to Hu's method with modifications performed in our laboratory as described ${ }^{21}$. The levels of thiols in each sample was calculated by using reduced glutathione as a standard thiol and the result was expressed in $\mu \mathrm{M}$.

\section{Glutathione assay}

At first, the serum was deproteinized with an equal volume of $5 \%$ sulfosalicylic acid (SSA) solution, centrifuged at $38000 \mathrm{rpm}$ for 10 minutes at $4{ }^{\circ} \mathrm{C}$ to remove precipitated proteins before being assayed for 
glutathione. Serum GSH was measured according to the modified method of Moron et al. ${ }^{22}$. Briefly, 200 $\mu \mathrm{L}$ of serum supernatant was mixed with $2 \mathrm{ml}$ of 200 $\mathrm{mM}$ phosphate buffer ( $\mathrm{pH} 8$ ) containing $0.6 \mathrm{mM} \mathrm{5,5}$ dithiobis (2-nitrobenzoic acid). Blank samples contained $2.5 \%$ SSA, instead of the supernatant. After 5 minutes incubation at room temperature, the absorbance was read at $405 \mathrm{~nm}$ against the blank sample. Reduced glutathione was dissolved in $2.5 \%$ SSA and was used as a standard. Serum GSH concentration was calculated using a standard curve and the result was expressed as $\mu \mathrm{M}$.

\section{Protein carbonyl assay}

Before PC determination, serum protein was diluted with phosphate buffer saline (PBS) to $4 \mathrm{mg} / \mathrm{mL}$. The levels of PC were measured by enzyme-linked immunosorbent assays (ELISA) using the commercially available kit (Cell Biolab, Inc, Company) as described by Buss et al. The results were presented as absorbance units in the ELISA reader.

\section{MDA assay}

MDA levels were measured according to the method of Uchiyama and Mihara ${ }^{23}$. Briefly, $3 \mathrm{~mL}$ of $1 \%$ orthophosphoric acid and $1 \mathrm{~mL}$ of $0.6 \% \mathrm{w} / \mathrm{v}$ aqueous solution of thiobarbituric acid were added to $0.5 \mathrm{ml}$ of serum. The mixture was heated for 45 minutes in a boiling water bath. After cooling, the mixture was centrifuged at $3000 \times \mathrm{g}$ for 10 minutes and the absorbance of the upper solution was determined at $535 \mathrm{~nm}$ against a blank sample containing $3 \mathrm{~mL}$ of phosphoric acid, $1 \mathrm{ml}$ thiobarbituric acid and $0.5 \mathrm{~mL}$ PBS. The concentration of MDA was calculated using 1,1,3,3-tetramethoxypropane standard curve and was expressed in $\mu \mathrm{M}$.

\section{Statistics analysis}

The results were presented as mean \pm standard deviation (SD) for quantitative variables. For the statistical analysis, the statistical software SPSS version 21.0 (SPSS Inc., Chicago, IL) was used. Numerical variables of groups were compared by the Student's unpaired t-test. Mann-Whitney $U$ test was also used to compare the numerical variables of subgroups. Categorical variables were compared using the chi-squared test. $\mathrm{P}$ values of less than 0.05 were considered statistically significant.

\section{RESULTS}

Demographic and clinical properties in migraine patients and healthy controls are presented in Table 1.
There was no significant difference in the mean ages of migraine and control groups (27.22 \pm 7.40 vs. $26.65 \pm$ $8.20, \mathrm{P}=0.77)$. Regarding to sex distribution, $67.4 \%$ of the migraine group and $66.6 \%$ of the healthy group were female and no difference in sex distribution was observed between subjects suffering from migraine and healthy individuals $(\mathrm{P}=0.57)$.

The levels of biochemical parameters in migraine patients and healthy controls are shown in Table 2. The mean serum levels of MDA ( $4.10 \pm 0.70$ vs. $3.20 \pm$ $0.62, \mathrm{P}=0.003)$, TOS $(18.46 \pm 4.06$ vs. $16.21 \pm 3.67$, $\mathrm{P}=0.007)$ and OSI (1.54 \pm 0.60 vs. $1.22 \pm 0.46, \mathrm{P}$ $=0.006$ ) were significantly higher in migraine group than those in the healthy group. PC concentration was slightly higher in the migraine group compared to healthy controls $(0.615 \pm 0.161 v s .0 .517 \pm 0.126)$, but the difference was not statistically significant $(P=0.1)$. The levels of T-SH $(273 \pm 51.71$ vs. $310.88 \pm 53.32, \mathrm{P}=$ $0.001)$, GSH $(28.08 \pm 6.20$ vs. $32.13 \pm 5.8, \mathrm{P}=0.002)$ and TAC $(1.27 \pm 0.226$ vs. $1.41 \pm 0.26, \mathrm{P}=0.01)$ were significantly lower in patients with the migraine compared to healthy control individuals.

The results of oxidative-antioxidative balance between migraine patients with and without aura are shown in Table 3. There was no statistically significant difference in serum levels of MDA (4.00 \pm 0.65 vs. $4.2 \pm$ $0.78, \mathrm{P}=0.056)$, TOS ( $18.28 \pm 3.55$ vs. $18.56 \pm 4.36$, $\mathrm{P}=0.7)$ and OSI $(1.46 \pm 0.5$ vs. $1.58 \pm 0.64, \mathrm{P}=0.56)$ between migraine patients with and without aura. We also found no significant difference in the levels of $\mathrm{T}$ $\mathrm{SH}(280.18 \pm 53.07$ vs. $269.56 \pm 51.50, \mathrm{P}=0.55), \mathrm{GSH}$ (29.56 \pm 5.57 vs. $27.30 \pm 6.46, \mathrm{P}=0.23), \mathrm{TAC}(1.33$ \pm 0.255 vs. $1.24 \pm 0.27, \mathrm{P}=0.3)$ and $\mathrm{PC}$ concentration $(0.574 \pm 0.16$ vs. $0.663 \pm 0.16, \mathrm{P}=0.3)$ between migraine patients with and without aura.

\section{DISCUSSION}

In the current study, it was hypothesized that oxidant increment and/or antioxidant depletion might be two major fundaments of the pathophysiology of migraine headache. Accordingly, we determined PC, MDA, TOS and OSI as the indicators for the activation of oxidative stress and TAC, T-SH and GSH as the markers of antioxidant status. To the best of our knowledge, this is the first to study the association between oxidative stress and migraine attack in an Iranian population sample. Overall, our results revealed that migraine attacks are associated with an increase in oxidant levels and a depletion of antioxidant defenses, which suggests a shift in oxidativeantioxidative balance towards oxidative status. The results confirmed our hypothesis and are consistent with other studies. Several studies have shown the 
Table 1: Demographicand clinical properties in patients with migraine and healthy controls (Mean \pm SD)

\begin{tabular}{llll}
\hline Parameter & Healthy control $(\mathbf{N}=\mathbf{4 5})$ & $\begin{array}{l}\text { Migraine patients } \\
(\mathbf{N}=\mathbf{4 6})\end{array}$ & P value \\
Sex (Female/Male) & $30 / 15$ & $30 / 16$ & 0.88 \\
Age (year) & $26.65 \pm 8.20$ & $27.22 \pm 7.40$ & 0.77 \\
Duration of migraine (years) & - & $4.56 \pm 2.62$ & - \\
Monthly frequency of headache & - & $5.13 \pm 2.25$ & - \\
Headache duration (hours) & - & $29.4 \pm 15.5$ & - \\
\hline
\end{tabular}

Table 2: The levels of biochemical parameters in migraine patients and healthy controls (Mean \pm SD)

\begin{tabular}{llll}
\hline Parameter & Healthy control $(\mathbf{N}=\mathbf{4 5})$ & $\begin{array}{l}\text { Migraine patients } \\
(\mathbf{N}=\mathbf{4 6})\end{array}$ & P value \\
$\begin{array}{l}\text { Total Antioxidant capacity } \\
(\mathrm{mM})\end{array}$ & $1.41 \pm 0.26$ & $1.27 \pm 0.226$ & 0.01 \\
$\begin{array}{l}\text { Total oxidant status }(\mu \mathrm{M}) \\
\text { Oxidative stress index }\end{array}$ & $16.21 \pm 3.67$ & $18.46 \pm 4.06$ & 0.007 \\
$\begin{array}{l}\text { (OSI) } \\
\text { Total thiol }(\mu \mathrm{M})\end{array}$ & $1.54 \pm 0.60$ & 0.006 \\
Reduced glutathione $(\mu \mathrm{M})$ & $32.13 \pm 5.8$ & $273 \pm 51.71$ & 0.001 \\
Protein carbonyl $(\mathrm{OD})$ & $0.517 \pm 0.126$ & $28.08 \pm 6.20$ & 0.002 \\
MDA $(\mu \mathrm{M})$ & $3.20 \pm 0.62$ & $0.615 \pm 0.161$ & 0.1 \\
\hline
\end{tabular}

Table 3: The levels of biochemical parameters in migraine patients with or without aura (Mean \pm SD)

\begin{tabular}{llll}
\hline Parameter & $\begin{array}{l}\text { Migraine with aura }(\mathbf{N}= \\
\mathbf{1 5})\end{array}$ & Migraine without aura $(\mathbf{N}=\mathbf{3 1})$ & P value \\
Sex (Female/Male) & $12 / 4$ & $18 / 12$ & 0.35 \\
Age (year) & $28.06 \pm 7.36$ & $26.33 \pm 7.60$ & 0.52 \\
$\begin{array}{l}\text { Total Antioxidant capacity } \\
\text { (mM) }\end{array}$ & $1.33 \pm 0.255$ & $1.24 \pm 0.27$ & 0.3 \\
Total oxidant status $(\mu \mathrm{M})$ & $18.28 \pm 3.55$ & $18.56 \pm 4.36$ & 0.7 \\
$\begin{array}{l}\text { Oxidative stress index } \\
\text { (OSI) }\end{array}$ & $1.46 \pm 0.5$ & $1.58 \pm 0.64$ & 0.56 \\
Total thiol $(\mu \mathrm{M})$ & & 0.55 \\
Reduced glutathione $(\mu \mathrm{M})$ & $29.56 \pm 5.57$ & $269.56 \pm 51.50$ & 0.23 \\
Protein carbonyl $(\mathrm{OD})$ & $0.574 \pm 0.16$ & $27.30 \pm 6.46$ & 0.3 \\
MDA $(\mu \mathrm{M})$ & $4.00 \pm 0.65$ & $0.663 \pm 0.16$ & 0.56 \\
\hline
\end{tabular}


elevated levels of MDA, a product of oxidative damage of lipids, in the blood of migraine patients when compared to controls ${ }^{24-26}$. In a study by Alp et al. ${ }^{27}$, the levels of total antioxidants were significantly lower in migraine patients while TOS and OSI were higher when compared to healthy individuals. Gupta et al. showed an increase in plasma levels of MDA and total antioxidant capacity in migraine patients ${ }^{28}$. Our TAC results are consistent with those of Alp et al., but did not confirm the results of Guptal et al. Moreover, the disturbance of antioxidant enzyme activities in serum and erythrocytes of migraine patients have been reported in several studies ${ }^{15,25}$.

Thiols are physiological free radical scavengers that represents approximately $53 \%$ of total antioxidants present in serum ${ }^{19}$. In the present study, low levels of GSH and T-SH in migraine patients indicate the occurrence of oxidative stress during migraine attack. Alp et al. also found lower levels of total thiols in migraine patients and detected a negative correlation between the duration of pain and thiol levels ${ }^{27}$. Similar to the study conducted by Bernecker et al., we found higher levels of PC in migraine patients compared to controls, however, the difference between the two groups was not statistically significant ${ }^{29}$. Carbonyl groups of proteins can be induced by almost all types of ROS, and high levels of these proteins are reflective of high levels of oxidative stress ${ }^{14}$.

Findings of the current and previous studies suggest that oxidative stress are likely to occur during migraine attacks. Also, there is evidence that oxidative stress and nitrosative stress (another form of oxidative-antioxidative imbalance) are involved in the pathophysiology of migraine ${ }^{26,30}$. Environmental factors that increase the probability of migraine attacks (so-called migraine triggers) such as alcohol, air pollutants and cigarette smoke commonly have a capacity to induce oxidative stress ${ }^{18}$. Moreover, studies have shown that Flunarizine, vitamin $\mathrm{C}$, vitamin $\mathrm{E}$, and coenzyme $\mathrm{Q}_{10}$, which are used in migraine prevention, decrease oxidative stress via their ROS scavenger properties ${ }^{24,31,32}$. These studies and our study show that irrespectively of environmental and genetic factors, migraine attack is associated with the occurrence of oxidative stress, however, it is not known how oxidative stress triggers a migraine attack. It is suggested that several oxidative stress-related mechanisms contribute to migraine pathogenesis. So far, two major theories of vascular and neurovascular origins have been suggested in migraine pathophysiology. Based on the vascular theory that was first presented by Graham and Wolff, the dilation of cerebral vessels could be a cause of migraine headache ${ }^{33}$. One major mechanism of vasodilation is the activation of ATP-sensitive and calcium-activated potassium channels in cerebral vascular muscle ${ }^{34}$. There is evidence that ROS, such as hydrogen peroxide and peroxynitrite (a product of the reaction of nitric oxide with superoxide), reversibly causes cerebral vasodilation by activating ATP-sensitive potassium channels most probably through an oxidant mechanism; whereas superoxide dilates cerebral vessels by opening calciumactivated potassium channels ${ }^{35,36}$. In another study, it was shown that the effect of ROS on ATP-sensitive potassium channels of the cells in the cerebral arterioles is blocked by antioxidants ${ }^{37}$.

The neurovascular theory has integrated both vascular and neurological events occurring in migraine. Base on this theory, migraine headache is associated with the inflammation of the meninges, particularly the dura ${ }^{38}$. During migraine attack, the trigeminal sensory nerves innervating dural blood vessels become extra sensitive and release vasoactive modulatory neuropeptides such as the neurokinins, substance $\mathrm{P}$ and calcitonin gene-related peptides (CGRP), which may play a role in meningeal inflammation and migraine pain ${ }^{38-40}$. This theory also implicates the phenomenon of cortical spreading depression as an underlying mechanism of migraine aura ${ }^{40}$. There is evidence that increased oxidative stress contributes to various pathological states including trigeminovascular inflammation, which occurs during migraine attacks ${ }^{41,42}$. It has been shown that ROS, including $\mathrm{H}_{2} \mathrm{O}_{2}$, can activate sensory neurons directly and/or indirectly by releasing endogenous CGRP as a mediator of migraine headache ${ }^{43}$.

\section{CONCLUSIONS}

This study showed that oxidative-antioxidative balance shifts towards oxidative status during migraine attack. An increase in oxidant levels, either with or without the depletion of antioxidant activity, may contribute to migraine pathogenesis by affecting cerebral blood vessel diameter and by activating trigeminal sensory nerves innervating dural blood vessels.

\section{ABBREVIATIONS}
PC: Protein carbonyl
MDA: Malondialdehyde
TOS: Total oxidants status
T-SH: Total thiols
GSH: Glutathione
TAC: Aantioxidant capacity
OSI: Oxidative stress index
ROS: Reactive oxygen species
SSA: Sulfosalicylic acid 
ELISA: Enzyme-linked immunosorbent assay

ABTS: 2, 2-azinobis 3-ethylbenzothiazoline-6sulfonate

CGRP: Calcitonin gene-related peptide

\section{COMPETING INTERESTS}

Authors have no conflict of interest.

\section{AUTHORS' CONTRIBUTIONS}

Alireza Khosravi: Design of the study, acquisition of data, and writing of the article.

Abdoreza Ghoreishi: Collection of data and revision of the article.

Alireza Nakhaee: Analysis and interpretation of data. Masoud Sadeghi: Revision of the article and final approval of the version to be published.

Zahra Arefpoor: Revision of the article.

\section{ACKNOWLEDGMENTS}

The authors thankfully acknowledge Zahedan University of Medical Sciences for support dissertation grant. They also are grateful to Dr. Khazaei for the English revision of the manuscript. In addition, authors would like to thank the subjects who willingly participated in the study.

\section{REFERENCES}

1. Fattahian R, Sadeghi M, Mozaffari HR. The association between allergic rhinitis with migraine: A systematic review and meta-analysis study. Med Sci. 2018;22:225-31.

2. of the International Headache Society HCS. The International Classification of Headache Disorders: 2nd edition. Cephalalgia. 2004;24 Suppl 1:9-160. Headache Classification Subcommittee of the International Headache Society Guideline Journal Article England Cephalalgia. 2004;24 Suppl 1:9-160.

3. Wessman M, Terwindt GM, Kaunisto MA, Palotie A, Ophoff RA. Migraine: a complex genetic disorder. Lancet Neurol. 2007;6(6):521-32. Available from: 10.1016/s1474-4422(07) 70126-6.

4. Sparaco M, Feleppa M, Lipton R, Rapoport A, Bigal M. Mitochondrial dysfunction and migraine: evidence and hypotheses. Cephalalgia. 2006;26(4):361-72. Available from: 10.1111/ j.1468-2982.2005.01059.x.

5. Edvinsson L. Neuronal signal substances as biomarkers of migraine. Headache. 2006;46(7):1088-94. Available from: 10.1111/j.1526-4610.2006.00502.x.

6. Uttara B, Singh AV, Zamboni P, Mahajan RT. Oxidative stress and neurodegenerative diseases: a review of upstream and downstream antioxidant therapeutic options. Curr Neuropharmacol. 2009;7(1):65-74. Available from: 10.2174/ 157015909787602823.

7. Limon-Pacheco J, Gonsebatt ME. The role of antioxidants and antioxidant-related enzymes in protective responses to environmentally induced oxidative stress. Mutat Res. 2009;674(12):137-47. Available from: 10.1016/j.mrgentox.2008.09.015.

8. Eren $Y$, Dirik E, Neselioglu S, Erel O. Oxidative stress and decreased thiol level in patients with migraine: cross-sectional study. Acta Neurol Belg. 2015;115(4):643-9. Available from: 10.1007/s13760-015-0427-y.

9. Pham-Huy $L A, H e H$, Pham-Huy $C$. Free radicals, antioxidants in disease and health. Int J Biomed Sci. 2008;4(2):89-96.
10. Hu ML. Measurement of protein thiol groups and glutathione in plasma. Methods Enzymol. 1994;233:380-5. Available from: 10.1016/S0076-6879(94)33044-1.

11. Koracevic D, Koracevic G, Djordjevic V, Andrejevic S, Cosic V. Method for the measurement of antioxidant activity in human fluids. J Clin Pathol. 2001;54(5):356-61.

12. Cheeseman KH, Slater TF. An introduction to free radical biochemistry. Br Med Bull. 1993;49(3):481-93. Available from: 10.1093/oxfordjournals.bmb.a072625.

13. Finkel T, Holbrook NJ. Oxidants, oxidative stress and the biology of ageing. Nature. 2000;408(6809):239-47. Available from: 10.1038/35041687.

14. Dalle-Donne I, Rossi R, Giustarini D, Milzani A, Colombo R. Protein carbonyl groups as biomarkers of oxidative stress. Clin Chim Acta. 2003;329(1-2):23-38.

15. Boćkowski L, Sobaniec W, KuW, Smigielska-Kuzia J. Serum and intraerythrocyte antioxidant enzymes and lipid peroxides in children with migraine. Pharmacol Rep. 2008;60(4):542-8.

16. J JMM, Pérez-Gómez C, Castro IND. Antioxidant enzymes and human diseases. Clin Biochem. 1999;32(8):595-603.

17. Valko M, Leibfritz D, Moncol J, Cronin MT, Mazur M, Telse J. Free radicals and antioxidants in normal physiological functions and human disease. Int J Biochem Cell Biol. 2007;39(1):44-84. Available from: 10.1016/j.biocel.2006.07. 001.

18. Borkum JM. Migraine Triggers and Oxidative Stress: A Narrative Review and Synthesis. Headache. 2016;56(1):12-35. Available from: 10.1111/head.12725

19. Erel O. A novel automated method to measure total antioxidant response against potent free radical reactions. Clin Biochem. 2004;37(2):112-9.

20. Erel O. A new automated colorimetric method for measuring total oxidant status. Clin Biochem. 2005;38(12):1103-11. Available from: 10.1016/j.clinbiochem.2005.08.008.

21. Nakhaee A, Shahabizadeh F, Erfani M. Protein and lipid oxidative damage in healthy students during and after exam stress. Physiol Behav. 2013;13(118):118-21. Available from: 10.1016/j.physbeh.2013.05.028.

22. Moron MS, Depierre JW, Mannervik B. Levels of glutathione glutathione reductase and glutathione S-transferase activities in rat lung and liver. Biochim Biophys Acta. 1979;582(1):67-78

23. Mihara $\mathrm{M}$, Uchiyama $\mathrm{M}$. Determination of malonaldehyde precursor in tissues by thiobarbituric acid test. Anal Biochem. 1978;86(1):271-8.

24. Ciancarelli I, Tozzi-Ciancarelli M, Massimo CD, Marini C, Carolei A. Flunarizine effects on oxidative stress in migraine patients. Cephalalgia. 2004;24(7):528-32. Available from: 10.1111/j.1468-2982.2003.00705.x.

25. Tuncel D, Tolun Fl, Gokce M, Imrek S, Ekerbiçer H. Oxidative stress in migraine with and without aura. Biol Trace Elem Res. 2008;126(1-3):92-7. Available from: 10.1007/s12011-008$8193-9$.

26. Yilmaz G, Sürer H, Inan LE, Coskun Ö, Yücel D. Increased nitrosative and oxidative stress in platelets of migraine patients. Tohoku J Exp Med. 2007;211(1):23-30.

27. Alp R, Selek S, Alp SI, Taşkin A, Koçyiğit A. Oxidative and antioxidative balance in patients of migraine. Eur Rev Med Pharmacol Sci. 2010;14(10):877-82.

28. Gupta R, Pathak R, Bhatia MS, Banerjee BD. Comparison of oxidative stress among migraineurs, tension-type headache subjects, and a control group. Ann Indian Acad Neurol. 2009;12(3):167-172. Available from: 10.4103/0972-2327. 56316.

29. Bernecker C, Ragginer C, Fauler G, Horejsi R, Möller R, Zelzer $\mathrm{S}$. Oxidative stress is associated with migraine and migraine-related metabolic risk in females. Eur J Neurol. 2011;18(10):1233-9. Available from: 10.1111/j.1468-1331 2011.03414x.

30. Gruber HJ, Bernecker C, Lechner A, Weiss S, Wallner-Blazek M, Meinitzer A. Increased nitric oxide stress is associated with migraine. Cephalalgia. 2010;30(4):486-92. Available from: 10 1111/j.1468-2982.2009.01964.x. 
31. Chayasirisobhon S. Use of a pine bark extract and antioxidant vitamin combination product as therapy for migraine in patients refractory to pharmacologic medication. Headache. 2006;46(5):788-93. Available from: 10.1111/j.1526-4610.2006 00454.x.

32. Gaul C, Diener HC, Danesch U. Improvement of migraine symptoms with a proprietary supplement containing riboflavin, magnesium and Q10: a randomized, placebocontrolled, double-blind, multicenter trial. J Headache Pain. 2015;16(32). Available from: 10.1186/s10194-015-0516-6.

33. Graham JR, Wolff HG. Mechanism of migraine headache and action of ergotamine tartrate. Arch Neurol Psychiatry. 1938;39(4):737-763. Available from: 10.1001/archneurpsyc. 1938.02270040093005.

34. Kitazono T, Faraci FM, Taguchi H, Heistad DD. Role of potassium channels in cerebral blood vessels. Stroke. 1995;26(9):1713-23. Available from: 10.1161/01.STR.26.9. 1713.

35. Faraci FM. Reactive oxygen species: influence on cerebral vascular tone. J Appl Physiol (1985). 2006;100(2):739-43. Available from: 10.1152/japplphysiol.01044.2005.

36. Wei EP, Kontos HA, Beckman JS. Mechanisms of cerebral vasodilation by superoxide, hydrogen peroxide, and peroxynitrite. Am J Physiol. 1996;271(3 Pt 2):H1262-6. Available from: 10.1152/ajpheart.1996.271.3.H1262.

37. Wei EP, Kontos HA, Beckman JS. Antioxidants inhibit ATPsensitive potassium channels in cerebral arterioles. Stroke.
1998;29(4):817-22. Available from: 10.1161/01.STR.29.4.817.

38. Moskowitz MA. Neurogenic inflammation in the pathophysiology and treatment of migraine. Neurology. 1993;43(6):S16-

39. Arulmozhi DK, Veeranjaneyulu A, Bodhankar SL. Migraine: current concepts and emerging therapies. Vascul Pharmacol. 2005;43(3):176-87. Available from: 10.1016/j.vph.2005.07.001

40. Galletti F, Cupini LM, Corbelli I, Calabresi P, Sarchielli P. Pathophysiological basis of migraine prophylaxis. Prog Neurobiol. 2009;89(2):176-92. Available from: 10.1016/j.pneurobio.2009. 07.005 .

41. Andersson DA, Gentry C, Moss S, Bevan S. Transient receptor potential $A 1$ is a sensory receptor for multiple products of oxidative stress. J Neurosci. 2008;28(10):2485-94. Available from: 10.1523/JNEUROSCI.5369-07.2008.

42. Keeble JE, Bodkin JV, Liang L, Wodarski R, Davies M, Fernandes ES. Hydrogen peroxide is a novel mediator of inflammatory hyperalgesia, acting via transient receptor potentia vanilloid 1-dependent and independent mechanisms. Pain. 2009;141(1-2):135-42. Available from: 10.1016/j.pain.2008.10. 025 .

43. Shatillo A, Koroleva K, Giniatullina R, Naumenko N, Slastnikova AA, Aliev RR. Cortical spreading depression induces oxidative stress in the trigeminal nociceptive system. Neuroscience. 2013;253:341-9. Available from: 10.1016/j.neuroscience.2013. 09.002 